\title{
Raman spectroscopy of shocked gypsum from a meteorite impact crater
}

\author{
Connor Brolly, John Parnell and Stephen Bowden \\ Department of Geology \& Petroleum Geology, University of Aberdeen, Meston Building, Aberdeen, UK e-mail: c.brolly@ \\ abdn.ac.uk
}

\begin{abstract}
Impact craters and associated hydrothermal systems are regarded as sites within which life could originate on Earth, and on Mars. The Haughton impact crater, one of the most well preserved craters on Earth, is abundant in Ca-sulphates. Selenite, a transparent form of gypsum, has been colonized by viable cyanobacteria. Basement rocks, which have been shocked, are more abundant in endolithic organisms, when compared with unshocked basement. We infer that selenitic and shocked gypsum are more suitable for microbial colonization and have enhanced habitability. This is analogous to many Martian craters, such as Gale Crater, which has sulphate deposits in a central layered mound, thought to be formed by post-impact hydrothermal springs. In preparation for the 2020 ExoMars mission, experiments were conducted to determine whether Raman spectroscopy can distinguish between gypsum with different degrees of habitability. Ca-sulphates were analysed using Raman spectroscopy and results show no significant statistical difference between gypsum that has experienced shock by meteorite impact and gypsum, which has been dissolved and re-precipitated as an evaporitic crust. Raman spectroscopy is able to distinguish between selenite and unaltered gypsum. This shows that Raman spectroscopy can identify more habitable forms of gypsum, and demonstrates the current capabilities of Raman spectroscopy for the interpretation of gypsum habitability.

Received 31 May 2016, accepted 19 August 2016, first published online 21 September 2016
\end{abstract}

Key words: habitability, impact crater, Raman spectroscopy, shocked gypsum.

\section{Introduction}

Impact generated sulphate deposits and significance for life

Hydrothermal deposits within craters on Mars represent one of the most important targets in the search for life on Mars (Cabrol et al. 1999; Newsom et al. 2001). Hydrothermal systems are realistic sites to sustain life due to the presence of liquid $\mathrm{H}_{2} \mathrm{O}$, heat and dissolved nutrients and alkaline vents within these systems are considered to be locations where life could originate (Farmer \& Des Marais 1999; Newsom et al. 2001; Osinski et al. 2005; Lane \& Martin 2012). Over 60 impact craters with associated hydrothermal activity have been discovered on Earth, and given the long bombardment history of Mars, impact craters could be a common site to search for life (Chapman \& Jones 1977; Naumov 2002). Gale Crater has sulphates present within a layered sedimentary mound in the centre of the crater, named Mount Sharp, thought to be formed by hydrothermal springs, as there is a lack of features associated with lacustrine environments such as terraces, deltas and fans. (Rossi et al. 2008; Thomson et al. 2011; Schwenzer et al. 2012). Semi-hydrated Ca-sulphate, bassanite has been identified in Mawrth Vallis, one of the proposed landing sites for the ExoMars 2020 mission (Wray et al. 2010).

The Eocene Haughton impact crater, located on Devon Island in the Canadian High Arctic Archipelago, provides a useful analogue site to study post impact sulphate deposits (Sherlock et al. 2005). It is exceptionally well preserved, which is why it has been extensively studied, and has examples of sulphate deposits containing microbial life (Osinski \& Spray
2001; Parnell et al. 2004). The current structure is composed of a central uplift overlaid with melt breccia, which is the most common impactite (Lindgren et al. 2009). There is a gneissic crystalline basement, which is shocked and is inhabited by endolithic photosynthetic microorganisms. These organisms are more abundant in the shocked material due to an increased pore space as a result of impact fracturing, and increased translucence due to vaporization of opaque mineral phases (Cockell et al. 2002). The target rock included gypsum bearing carbonate rocks, Ordovician in age (Robertson \& Sweeney 1983). Impact remobilized sulphate occurs as selenite, a transparent form of gypsum (CaSO4.2(H2O)), which cross-cuts the melt breccia as veins. Viable, extant cyanobacterial colonies are present within the selenite and are black in colour due to the UV protective pigments scytonemin and gloeocapsin (Cockell et al. 2002, 2003). Mobilization still occurs at present in the form of evaporitic crusts on bedrock surfaces and soil (Parnell et al. 2004).

Given that sulphates formed by hydrothermal activity are habitable substrates, and that shocking increases the space for an organism to exploit; shocked sulphates are important targets with which to find evidence of microbial life. If instrumentation could distinguish between shocked and un-shocked phases, and between various sulphate phases, this would be beneficial when identifying the most likely sulphates to contain life signatures.

\section{Raman for Mars}

Raman spectroscopy uses a monochromatic laser light source to irradiate a sample. Majority of the light, which interacts 


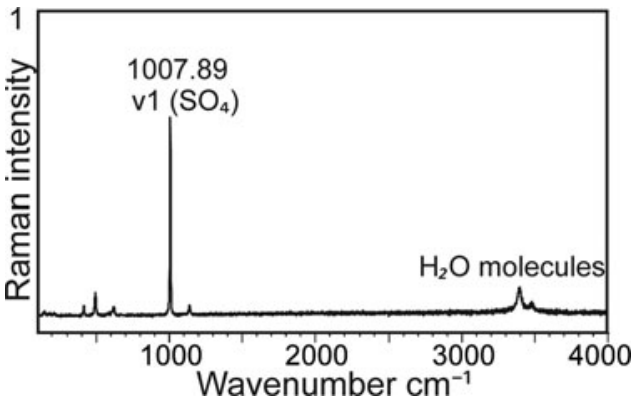

Fig. 1. Extended spectra $100-4000 \mathrm{~cm}^{-1}$ showing v1 sulphate symmetric stretching mode $\left(1007.89 \mathrm{~cm}^{-1}\right)$ and stretching mode of $\mathrm{H}_{2} \mathrm{O}\left(\sim 3450 \mathrm{~cm}^{-1}\right)$.

with the sample is scattered elastically, with no change in wavelength. However a small proportion of the light is scattered inelastically - either an increase or decrease in wavelength, known as Raman scattering. Raman spectroscopy produces a vibrational 'fingerprint', which is dependent on the vibrational state of molecules in a given compound (Ellery \& Wynn-Williams 2003).

The popularity of Raman spectroscopy has dramatically increased in the last 30 years due to its increasing range of applications (Pérez \& Martinez-Frias 2006). It is a useful astrobiological tool as it is a non-destructive technique, which is able to be miniaturized. It is sensitive to carbonaceous materials, which is one of the main targets of the ESA ExoMars mission but it is also sensitive to various microbial pigments, such as chlorophylls, carotenoids and scytonemin, which increase its appeal (Ellery \& Wynn-Williams 2003; Jehlička et al. 2014). It has a wavelength range covering most vibrational modes including carbonates, silicates and sulphates (i.e. most rock-forming minerals), therefore it can also be used for petrographic analysis (Haskin et al. 1997; Wang et al. 1998).

\section{Raman spectroscopy of gypsum and impact shocked gypsum}

The Raman spectrum of gypsum characteristically shows a narrow intense band around 1008 reciprocal centimetres $\left(\mathrm{cm}^{-1}\right)$, which is the v1 sulphate symmetric stretching mode, herein referred to as v1 sulphate band. The stretching modes of water occur around $3450 \mathrm{~cm}^{-1}$ (Berenblut et al. 1970; Krishnamurthy \& Soots 1971), shown in Fig. 1.

The astrobiological community is interested in the effect of shocking on sulphates as they occur on Mars. Micro-scale deformation experiments of gypsum by Hogan et al. (2012), show that the v1 sulphate band is least intense at the centre of deformation, where most load was experienced, and most intense at the outer margins of the deformation structure where least load was experienced. This is evidence that shocking reduces the v1 sulphate stretching band intensity. Instantaneous compressional deformation occurs in both meteorite (macro) shock events and micro-indentation experiments.

The effects of shock on gypsum have been discussed by Ramkissoon et al. (2014), using impact shock experiments with a two stage light gas gun and projectile, fired at plaster of Paris (gypsum). Their experiments show that

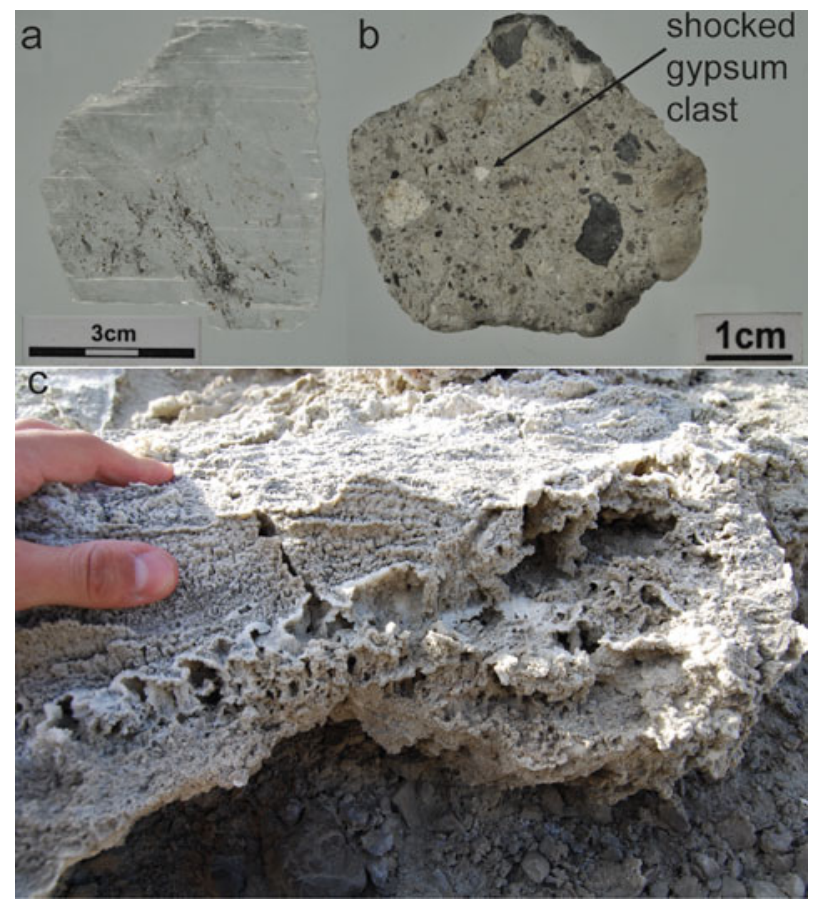

Fig. 2. Sample photographs. (a) Selenite, Haughton crater (S2), showing black pigmentation of bacterial colonies. (b) Melt breccia, Haughton crater (SH1), showing fragment of shocked gypsum. (c) Evaporitic gypsum crust, Haughton crater (C1).

Table 1. Table of sample locations and ages

\begin{tabular}{|c|c|c|c|}
\hline Sample & Description/location & Age & Group \\
\hline U1 & Vale of Eden, Cumbria, UK & Permian & 1 \\
\hline $\mathrm{U} 2$ & $\begin{array}{l}\text { Kingscourt fibrous, Co. } \\
\text { Cavan, Ireland }\end{array}$ & Triassic & 1 \\
\hline U3 & Scapa, Orkney & Devonian & 1 \\
\hline U4 & $\begin{array}{l}\text { Kingscourt with hematite, } \\
\text { Co. Cavan, Ireland }\end{array}$ & Triassic & 1 \\
\hline U5 & Gotham Triassic, England & Triassic & 1 \\
\hline U6 & Ebro Basin, Spain & Oligocene-Miocene & 1 \\
\hline S1 & Selenite, California & Paleogene & 2 \\
\hline S2 & $\begin{array}{l}\text { Selenite, Haughton, Devon } \\
\text { Island }\end{array}$ & Eocene-Oligocene & 2 \\
\hline S3 & $\begin{array}{l}\text { GSC dome (NE side), } \\
\text { Selenite Haughton, Devon } \\
\text { Island }\end{array}$ & Eocene-Oligocene & 2 \\
\hline S4 & Selenite, Kent & Eocene & 2 \\
\hline $\mathrm{C} 1$ & $\begin{array}{l}\text { Central uplift crust, } \\
\text { Haughton, Devon Island }\end{array}$ & Eocene-Holocene & 3 \\
\hline $\mathrm{C} 2$ & $\begin{array}{l}\text { GSC dome (NE side) crust, } \\
\text { Haughton, Devon Island }\end{array}$ & Eocene-Holocene & 3 \\
\hline $\mathrm{C} 3$ & Gypcrete Chile & $\begin{array}{l}\text { Paleogene - } \\
\text { Holocene }\end{array}$ & 3 \\
\hline $\mathrm{C} 4$ & $\begin{array}{l}\text { Rhino Creek, Crust on lake } \\
\text { sediments, Haughton, Devon } \\
\text { Island }\end{array}$ & Eocene-Holocene & 3 \\
\hline SH1 & $\begin{array}{l}\text { West Rhino creek melt brec- } \\
\text { cia, Haughton, Devon Island }\end{array}$ & Eocene & 4 \\
\hline $\mathrm{SH} 2$ & $\begin{array}{l}\text { Gemini Hills Shocked A } \\
\text { Haughton, Devon Island }\end{array}$ & Eocene & 4 \\
\hline $\mathrm{SH} 3$ & $\begin{array}{l}\text { Gemini Hills Shocked B } \\
\text { Haughton, Devon Island }\end{array}$ & Eocene & 4 \\
\hline
\end{tabular}




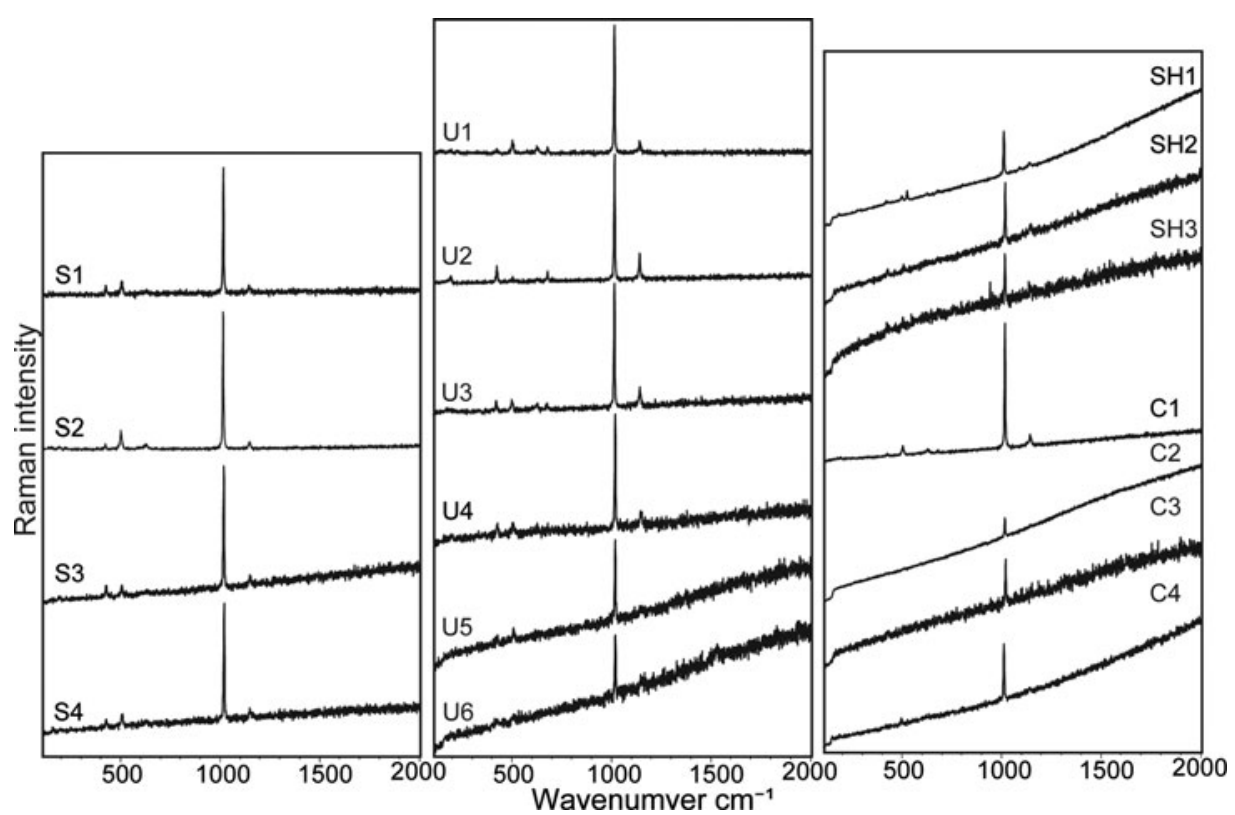

Fig. 3. Extended Raman spectra for gypsum $\left(100-2000 \mathrm{~cm}^{-1}\right)$. $x$-axis is Raman shift in reciprocal centimetres $\left(\mathrm{cm}^{-1}\right)$. $y$-axis is Raman intensity in arbitrary units (a.u.). 'SH' spectra have experienced shock from meteoric impact. ' $\mathrm{C}$ ' spectra are gypsum samples, which have been dissolved then re-precipitated as evaporitic crusts. 'S' spectra are selenite, a transparent form of gypsum. 'U' spectra are from unaltered gypsum samples unaffected by shock or dissolution and re-precipitation.

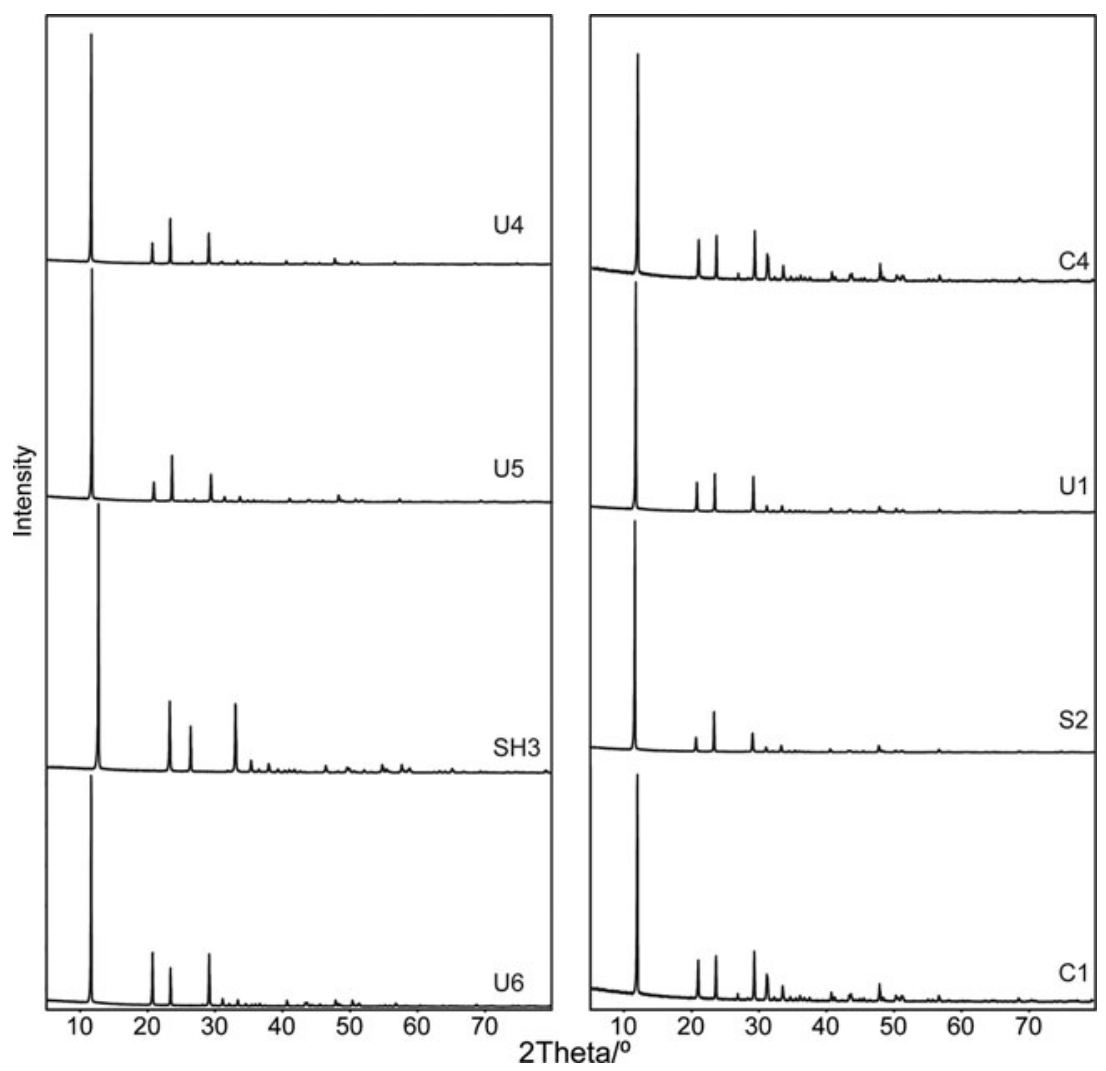

Fig. 4. X-ray diffraction patterns.

devolatilization occurs as a result of the impact, based on the disappearance of water molecule bands around $3450 \mathrm{~cm}^{-1}$, and the shift of bands 427 and $487 \mathrm{~cm}^{-1}$, is indicative of anhydrite. Characterizing the dehydration of gypsum to anhydrite using Raman spectroscopy has been well studied and shows the sulphate stretching band exhibiting an increase in band position with increasing dehydration (Prasad et al. 2001; Liu et al. 2009). 
Bucio et al. (2015) used experimentally impact-shocked gypsum to characterize post-impact phases using Raman spectroscopy and X-ray diffraction (XRD). This study compared Raman spectra obtained from naturally shocked samples with Raman spectra obtained from experimentally impactshocked gypsum, published by previous authors, to assess if the spectral changes associated with shock are comparable, and ultimately if shocked gypsum can be differentiated from other phases of gypsum. The spectral changes were analysed by comparing v1 sulphate band positions against band widths, referred to as the full width at half maximum (FWHM).

\section{Methods}

\section{Samples}

Gypsum samples were separated into four groups:

(1) Unaltered gypsum - samples which have not experienced shock or dissolution and subsequent re-precipitation. The crystal habits range from grainy to massive or fibrous.

(2) Selenite - a transparent form of gypsum, which has a distinct platy crystal habit. Selenite at the Haughton structure formed by the dissolution of gypsum in the target rock, and circulated the structure before re-precipitating as selenite.

(3) Crusts - sulphate rich waters at the Haughton flows over the surface topography and slowly evaporates, leaving a mineral 'crust' on outcropped rock and soil.

(4) Shocked gypsum - samples include a primary shocked gypsum nodule, and shocked gypsum fragments within melt breccia (see Fig. 2).

The majority of the samples originate from the Haughton impact crater, Devon Island, Canada; see Table 1 for more information on sample locations and ages. Minimal sample preparation was employed, simulating capabilities during a remote mission on Mars. If necessary, samples were cut to expose the sulphate, however where possible rough untreated surfaces were analysed. This study would be equally appropriate for the NASA 2020, SHERLOC instrument, which will have spatial mapping capabilities (Beegle et al. 2015).

\section{Raman spectroscopy configuration}

Raman spectra were obtained using a Renishaw InVia H36031 confocal Raman microscope operating at a wavelength of $514.5 \mathrm{~nm}$ green monochromatic laser light, which is similar to the ExoMars flight instrument wavelength of $532 \mathrm{~nm}$ (Rull et al. 2011). The laser power was $0.3 \mathrm{~mW}$, avoiding laser induced heating of samples. A $50 \times$ objective lens was used giving a laser 'footprint' of 1-3 $\mu \mathrm{m}$ in diameter, with an extended spectral range of $100-2000 \mathrm{~cm}^{-1} .10 \mathrm{~s}$ exposure time and 1 accumulation were acquired for each spectrum, giving a good signal-to-noise ratio. To include the stretching modes of water molecules, extended wavelength $\left(100-4000 \mathrm{~cm}^{-1}\right)$ was also measured using the above settings. Spectra were processed using a smooth, baseline subtraction and peak fit functions using WiRE 2.0 software. Peak fitting used a mixture of Gaussian and Lorentzian algorithms.

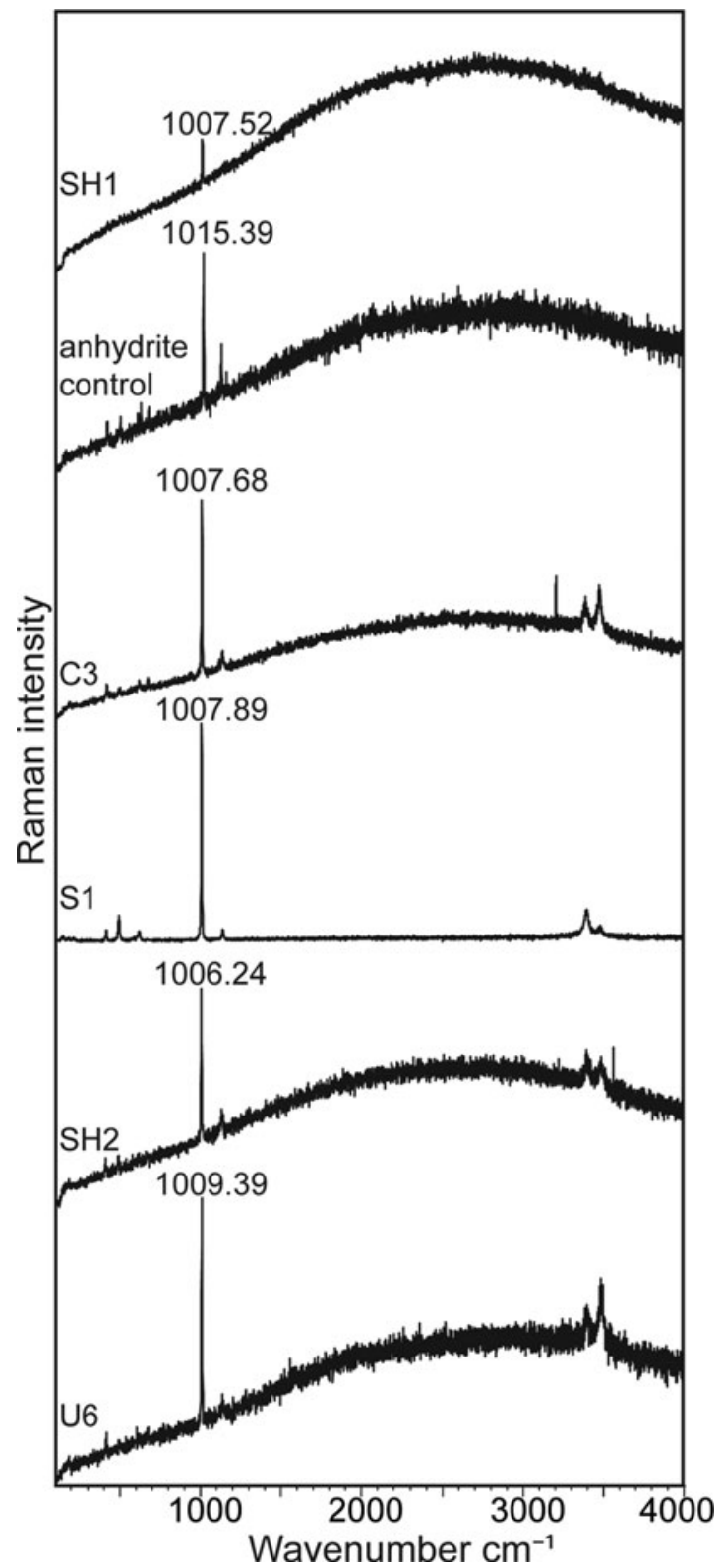

Fig. 5. Extended Raman spectra for gypsum and anhydrite (100$4000 \mathrm{~cm}^{-1}$ ). Spectra include v1 sulphate stretching mode and $\mathrm{H}_{2} \mathrm{O}$ molecule stretching mode around $3500 \mathrm{~cm}^{-1}$.

\section{$X$-ray diffraction}

Diffraction patterns were acquired on powder samples by using an X'Pert diffractometer (PANalytical, NL) equipped with $\mathrm{Cu}-\mathrm{k} \alpha$ radiation $(1.54 \AA ; 45 \mathrm{kV} / 40 \mathrm{~mA})$ in $\theta-\theta$ reflectance geometry; data were collected from $5^{\circ}$ to $80^{\circ} 2 \theta$ with a step size of $0.013^{\circ}$ and a time-per-step of $13.77 \mathrm{~s}$. Crystalline phases were identified by comparison with ICDD PDF \# [01-074-1433] (Gypsum). Samples were powdered by hand using a pestle and mortar.

\section{Spectral parameter analysis}

Ten spectra were obtained from each sample and average FWHM were plotted against sulphate band positions. 
(a)

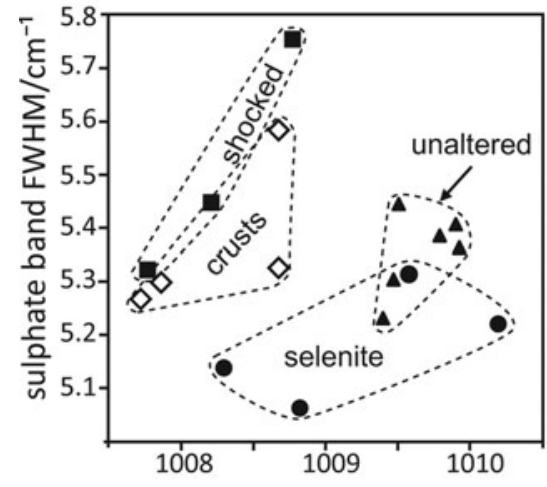

(b)

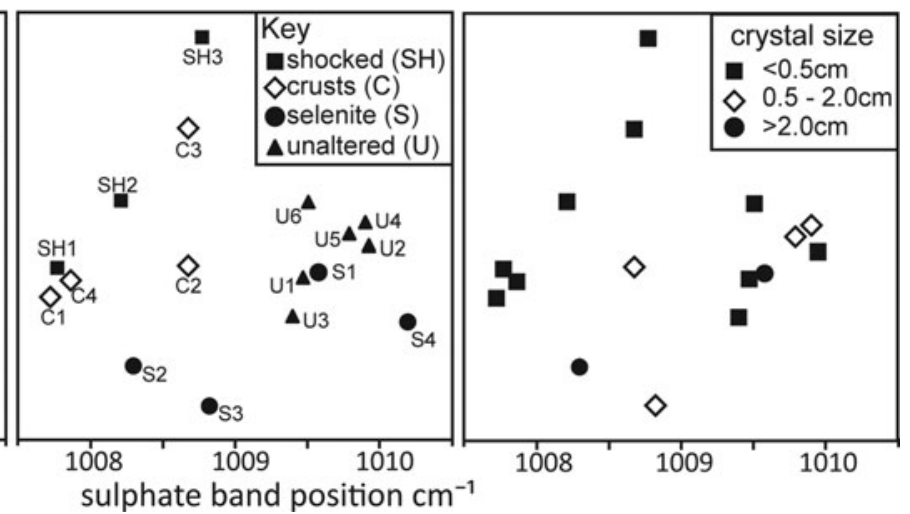

Fig. 6. Sulphate band position against sulphate band full width at half maximum (FWHM), with each point representing an average of ten spectra. $x$-axis, is the sulphate (v1) band position in reciprocal centimetres $\left(\mathrm{cm}^{-1}\right) \cdot y$-axis, is the sulphate (v1) FWHM. (a) Samples are separated into their geological groups. (b) Samples are distinguished by sample classification (Table 1). (c) Samples are distinguished based on crystal size. Squares denote a crystal size $<0.5 \mathrm{~cm}$; diamonds denote a crystal size between 0.5 and $2 \mathrm{~cm}$; circles denote a crystal size $>2 \mathrm{~cm}$.

Statistical variance tests were used to determine if sample groups are statistically different from each another.

\section{Statistical analysis}

Overlapping sample fields were examined using SigmaPlot statistical software package to confirm if the groups were statistically different. The sample groups failed the normality test therefore a non-parametric test was used. As two independent groups were compared, a Man-Whitney U test was used.

\section{Results}

\section{Raman spectroscopy}

The spectra obtained across the sample set all show a v1 sulphate band position of around $1008 \mathrm{~cm}^{-1}$, which is indicative of gypsum (Krishnamurthy \& Soots 1971), shown in Fig. 3. The shocked samples, SH2 and SH3, show a sloping baseline with increased signal-to-noise ratio compared with other samples e.g. selenite. Additionally the shocked samples show a weaker Raman signal, with lower band intensities. The spectra from evaporitic crusts are similar spectra to that of shocked samples, with low intensity bands and a higher signal-to-noise ratio, a part from the central uplift crust, which has an improved signal-to-noise ratio. The selenite group, have the cleanest spectra with intense v1 sulphate bands and a better signal-to-noise ratio relative to the shocked samples. Unaltered samples show similar spectra to selenite, except from U6 and U5, which have increased signal-to-noise ratios. Average v1 band positions for each are; unaltered (U) - 1009.615, selenite (S) 1009.261, shocked $(\mathrm{SH})-1008.251$, crusts (C) - 1008.262 $\mathrm{cm}^{-1}$. Based on these band positions all samples are classed as gypsum and have not experienced dehydration.

\section{$X$-ray diffraction}

Eight gypsum samples were selected from the larger sample set for XRD analysis (Fig. 4), which cover the $4 \mathrm{Ca}$-sulphate groups. The cell parameters for each sample show that all eight samples are in the form of gypsum. It is common for impact shocked sample to experience partial or complete dehydration, however basanite or anhydrite phases are not found in specimen SH3, which is consistent with the Raman measurements obtained.

\section{Discussion}

\section{Raman spectroscopy - extended spectra}

Selected samples were re-analysed using an extended wavelength range $\left(100-4000 \mathrm{~cm}^{-1}\right)$, to include the stretching modes of water molecules, shown in Fig. 5. An anhydrite control is included to show a completely dehydrated phase. As expected the anhydrite control shows a v1 sulphate band position of $1015.39 \mathrm{~cm}^{-1}$, and does not show the stretching modes of water molecules around $3450 \mathrm{~cm}^{-1}$. Sample SH1 has a fragment of gypsum, and the spectrum shows a v1 band position of $1007.52 \mathrm{~cm}^{-1}$, which is indicative of gypsum, although it does not show the presence of water molecules at the expected wavelength. As shocking promotes devolatilization, the loss of $\mathrm{H}_{2} \mathrm{O}$ molecules would be expected, and is well documented by other authors. Additionally, a change in v1 band position from 1008 to $1015 \mathrm{~cm}^{-1}$, would also be expected. Sample SH2 shows a band position of $1006.24 \mathrm{~cm}^{-1}$, and has the stretching modes of water molecules. This is indicative of gypsum, and suggests that either no dehydration has occurred, or that the specimens have been rehydrated.

Experimental work by Ramkissoon et al. (2014) and Bucio et al. (2015), clearly show that shocking by impact generates, semi-hydrated and completely hydrated $\mathrm{Ca}$-sulphate phases in the form of basanite and anhydrite, respectively. This can be seen in the v1 sulphate band positon and the presence, or absence, of the stretching modes of water molecules. This relationship does not appear to be realized in naturally impact shocked Ca-sulphates from Haughton crater.

\section{$v 1$ band position against band FWHM}

The sulphate band position was plotted against the FWHM to determine if these Raman parameters could distinguish 
between the gypsum specimens. Fig. 6(a) shows the four types of gypsum used in this study presented as fields. Each point is an average of ten spectra. Selenite has the largest field, which overlaps with unaltered samples. Selenite and unaltered fields plot independently from shocked or crust fields, showing that Raman spectroscopy can distinguish between certain phases of gypsum. The shocked field plots on the edge of the crusts field. Samples with overlapping fields were analysed for statistical significance. No significant difference was found between the shocked and crust sample band positions ( $P=0.966$, MannWhitney Sum test) and FWHM $(P=0.251)$, indicating that Raman spectroscopy cannot currently distinguish between impact shocked gypsum and gypsum, which has been dissolved and re-precipitated as a mineral crust. In contrast, a significant difference is evident between selenite and unaltered sample band positions $(P=0.045)$ and FWHM $(P=0.020)$. This shows that using the sulphate v1 band position versus FWHM, differences between gypsum phases are evident. Raman can therefore identify gypsum phases with enhanced habitability.

Figure 6(b) distinguishes samples according to their classification in Table 1. Figure 6(c) distinguishes samples according to crystal size, which was determined petrographically. However, there does not appear to be any control based on crystal size.

\section{Conclusions}

A range of gypsum samples were analysed using Raman spectroscopy, to determine if this technique can differentiate between Ca-sulphates, which have enhanced habitability, and those that do not. Results show that Raman spectroscopy cannot currently determine a significant difference between gypsum, which has been shocked by meteoric impact (enhancing the habitability), and gypsum, which has been dissolved and re-precipitated as an evaporitic crust. Raman spectroscopy is able to differentiate between unaltered gypsum and selenite by plotting $\mathrm{v} 1$ sulphate band position against v1 sulphate band FWHM, and as selenite has been found with viable extant microbial colonies at Haughton impact crater, it is regarded as having enhanced habitability.

The presence of $\mathrm{H}_{2} \mathrm{O}$ bands in spectra obtained from shocked samples highlights the complexity of Raman spectra observed from naturally shocked samples compared with experimental shock studies. This indicates current capabilities of Raman spectroscopy, for the interpretation of gypsum habitability, prior to its use on the European Space Agency's ExoMars 2020 mission.

\section{Acknowledgements}

This work was funded by STFC grant ST/L001233/1. The University of Aberdeen Raman facility was funded by the BBSRC grant BBC5125101. Thanks to Jo Duncan for XRD assistance.

\section{References}

Beegle, L. et al. (2015). SHERLOC: Scanning Habitable Environments with Raman \& Luminescence for Organics \& Chemicals. In Aerospace Conference, 1-8.

Berenblut, B.J., Dawson, P. \& Wilkinson, G.R. (1970). The Raman spectrum of gypsum. Spectrochimica Acta 27A, 1849-1863.

Bucio, L. et al. (2015). Phase transitions induced by shock compression on a gypsum mineral: X-ray and micro-Raman analysis. High Press. Res. 35(4), 355-362.

Cabrol, N.A. et al. (1999). Hydrogeologic evolution of Gale Crater and its relevance to the exobiological exploration of Mars. Icarus 139, 235-245.

Chapman, C.R. \& Jones, K.L. (1977). Cratering and obliteration history of Mars. Аппи. Rev. Earth Planet. Sci. 5, 515-540.

Cockell, C.S. et al. (2002). Impact-induced microbial endolithic habitats. Meteorit. Planet. Sci. 37, 1287-1298.

Cockell, C.S. et al. (2003). Measurements of microbial protection from ultraviolet radiation in polar terrestrial microhabitats. Polar Biol. 26, 62-69.

Ellery, A. \& Wynn-Williams, D. (2003). Why Raman spectroscopy on Mars ?a case of the right tool for the right job. Astrobiology 3(3), 565-579.

Farmer, J.D. \& Des Marais, D.J. (1999). Exploring for a record of ancient Martian life. J. Geophys. Res. 104, 26,977-26,995.

Haskin, L.A. et al. (1997). Raman spectroscopy for mineral identification and quantification for in situ planetary surface analysis : a point count method. J. Geophys. Res. 102(97), 19293-19306.

Hogan, J.D. et al. (2012). Micro-scale deformation of gypsum during micro-indentation loading. Int. J. Rock Mech. Mining Sci. 54, 140-149.

Jehlička, J., Edwards, H.G.M. \& Oren, A. (2014). Raman spectroscopy of microbial pigments. Appl. Environ. Microbiol. 80(11), 3286-3295.

Krishnamurthy, N. \& Soots, V. (1971). Raman spectrum of gypsum. Can. J. Phys. 49, 885-896.

Lane, N. \& Martin, W.F. (2012). The origin of membrane bioenergetics. Cell 151(7), 1406-1416.

Lindgren, P. et al. (2009). Preservation of biological markers in clasts within impact melt breccias from the Haughton impact structure, Devon Island. Astrobiology 9(4), 391-400.

Liu, Y., Wang, A. \& Freeman, J.J. (2009). Raman, MIR, and NIR spectroscopic study of calcium sulphates: Gypsum, bassanite, and anhydrite. In 40th Lunar and Planetary Science Conference. p. 2128.

Naumov, M.V. (2002). Impact-generated hydrothermal systems: Data from Popigai, Kara, and Puchezh-Katunki impact structures. In: Plado, J. and Pesonen, L.J. (Eds.), Impacts in Precambrian shields. Springer-Verlag, Berlin, pp. 117-171.

Newsom, H.E., Hagerty, J.J. \& Thorsos, I.E. (2001). Location and sampling of aqueous and hydrothermal deposits in Martian impact craters. Astrobiology 1(1), 71-88.

Osinski, G.R. \& Spray, J.G. (2001). Impact-generated carbonate melts: evidence from the Haughton structure, Canada. Earth Planet. Sci. Lett. 194(1-2), 17-29.

Osinski, G.R., Spray, J.G. \& Lee, P. (2005). A case study of impact-induced hydrothermal activity: the Haughton impact structure, Devon Island, Canadian High Arctic. Meteorit. Planet. Sci. 40(12), 1789-1812.

Parnell, J. et al. (2004). Microbial colonization in impact-generated hydrothermal sulphate deposits, Haughton impact structure, and implications for sulphates on Mars. Int. J. Astrobiol. 3(3), 247-256.

Pérez, F.R. \& Martinez-Frias, J. (2006). Raman spectroscopy goes to Mars. Spectrosc. Eur. 18(1), 18-21.

Prasad, P.S.R., Pradhan, A. \& Gowd, T.N. (2001). In situ micro-Raman investigation of dehydration mechanism in natural gypsum. Curr. Sci. 80 (9), 1203-1207.

Ramkissoon, N.K. et al. (2014). Examining impact induced mineral devolatilisation using Raman spectroscopy. In 45th Lunar and Planetary Science Conference. p. Abstract 1891.

Robertson, P.B. \& Sweeney, J.F. (1983). Haughton impact structure: structural and morphological aspects. Can. J. Earth Sci. 20(7), 1134-1151. 
Rossi, A.P. et al. (2008). Large-scale spring deposits on Mars? J. Geophys. Res. E: Planets 113(8), 1-17.

Rull, F. et al. (2011). The Raman Laser Spectrometer (RLS) on the ExoMars 2018 Rover Mission. In 42nd Lunar and Planetary Science Conference.

Schwenzer, S.P. et al. (2012). Gale crater: formation and post-impact hydrous environments. Planet. Space Sci. 70(1), 84-95.

Sherlock, S.C. et al. (2005). Re-evaluating the age of the Haughton impact event. Meteorit. Planet. Sci. 40(12), 1777-1787.
Thomson, B.J. et al. (2011). Constraints on the origin and evolution of the layered mound in Gale Crater, Mars using Mars Reconnaissance Orbiter data. Icarus 214(2), 413-432.

Wang, A., Haskin, L.A. \& Cortez, E. (1998). Prototype Raman spectroscopic sensor for in situ mineral characterization on planetary surfaces. Appl. Spectrosc. 52(4), 477-487.

Wray, J.J. et al. (2010). Identification of the Ca-sulfate bassanite in Mawrth Vallis, Mars. Icarus 209(2), 416-421. 